\title{
Efeito da Irrigação e Adubação na Disponibilidade e Composição Bromatológica da Massa Seca de Lâminas Foliares de Capim-Elefante ${ }^{1}$
}

\author{
Rogério dos Santos Lopes ${ }^{2}$, Dilermando Miranda da Fonseca ${ }^{3}$, Rubens Alves de Oliveira ${ }^{4}$, Alex \\ Carvalho Andrade ${ }^{5}$, Domicio do Nascimento Júnior ${ }^{3}$, Alessandra Gimenez Mascarenhas ${ }^{6}$
}

\begin{abstract}
RESUMO - Conduziu-se este experimento com o objetivo de avaliar o efeito da irrigação, acompanhada de doses crescentes de nitrogênio e potássio (100-80; 200-160; 300-240; 400-320, respectivamente $\mathrm{N}_{\text {e }} \mathrm{K}$ ), sobre a produção e composição bromatológica de lâminas foliares em pastagem de capim-elefante. O delineamento experimental foi o de blocos ao acaso com três repetições para os tratamentos de sequeiro e irrigado. As baixas temperaturas e as menores horas de luz no período seco do ano determinaram o baixo crescimento da planta forrageira, mesmo com a irrigação. No entanto, no verão, constatou-se rápido crescimento da planta forrageira sob irrigação, privilegiando o desenvolvimento de colmos em relação às lâminas foliares, determinando as menores relações para as maiores doses dos fertilizantes. As lâminas foliares sob irrigação também apresentaram os menores valores de proteína bruta e os maiores de FDN e FDA. Assim, manejos mais freqüentes em pastagens sob irrigação poderiam controlar o desenvolvimento dos colmos e disponibilizar material de melhor composição bromatológica.
\end{abstract}

Palavras-chave: água, composição bromatológica, nitrogênio, Pennisetum purpureum, potássio

\section{Effect of Irrigation and Fertilization in the Availability and Chemical Composition of Leaf Lamina Dry Mass of Elephantgrass}

\begin{abstract}
An experiment was carried out to evaluate the effect of irrigation, followed by increasing levels of nitrogen and potassium (100-80; 200-160; 300-240; 400-320, respectively $\mathrm{N}_{\text {and }} \mathrm{K}_{2} \mathrm{O}$ ), on the production and chemical composition of the leaf lamina at the elephantgrass. The experimental delineation was of blocks randomized with three repetitions for treatments irrigated and dry land. The low temperatures and the smallest light hours in the dry season determined the low plant forage growth, even with the irrigation. However, in the summer, there was fast growth of plant forage under irrigation, emphasizing the culm growth in relation to leaf laminas, determining the lower relations to the higher fertilizer levels. The leaf laminas under irrigation also showed the lower crude protein contents and higher NDF and ADF contents. So, more frequent managing in the irrigated pastures could control the culm growth and available material of better chemical composition.
\end{abstract}

Key Words: chemical composition, nitrogen, Pennisetum purpureum, potassium, water

\section{Introdução}

A baixa produção animal no Brasil, sobretudo no período de seca, é resultado da baixa disponibilidade e valor nutritivo da forragem nas pastagens tropicais nesta época, quando os produtores buscam alternativas para manter a produção, o que resulta, na maioria das vezes, em elevação do custo de produção. Diante disso, mais de $90 \%$ dos animais abatidos no Brasil, que são produzidos exclusivamente em pastagem, estão sujeitos a variações na idade de abate, obedecendo à distribuição anual de chuvas (FNP, 1998).
Neste contexto, a pressão para reduzir custos de produção, associada à demanda por novas tecnologias, é a principal proposta para a viabilização econômica da agropecuária brasileira.

Esta intensificação da produção animal em pastagem deve compatibilizar a relação planta $\mathrm{x}$ animal x solo x clima, com o objetivo de equalizar o estoque e o acúmulo de forragem com o desempenho animal e a produtividade desejada. É possível, portanto, otimizar a produção do pasto e dos animais, para garantir a sustentabilidade do sistema, permitindo a redução dos custos de produção e o aumento da

\footnotetext{
${ }^{1}$ Parte da tese apresentada à Universidade Federal de Viçosa (UFV), pelo primeiro autor, para obtenção do título de Doutor em Zootecnia. Projeto financiado pela FAPEMIG.

2 Fiscal Federal Agropecuário. DSPS/SDC/MAPA (rogeriolopes@agricultura.gov.br).

3 Professor do Departamento de Zootecnia da UFV (dfonseca@ufv.br).

4 Professor do Departamento de Engenharia Agrícola da UFV (ralves@ufv.br).

5 Zootecnista. Bolsista Recém-Doutor na UFLA (acandrade@ufla.br).

6 Professora da União Pioneira de Integração Social - UPIS (alessandra@upis.br).
} 
margem líquida na exploração da atividade pecuária (Nabinger, 1996).

No Brasil, por haver regiões com características peculiares, seria prudente adotar tecnologias específicas ou adaptáveis de modo a atender a essas carências e tornar o ciclo da pecuária brasileira mais curto, melhorando a qualidade e a produtividade do rebanho nacional (Cardoso, 2001).

A intensificação da produção em pastagem pode tornar-se uma alternativa viável com a utilização de espécies forrageiras de alto potencial produtivo, o que poderá proporcionar altas taxas de lotação. Entre essas espécies, o capim-elefante (Pennisetum purpureum, Schum.) tem-se destacado, principalmente, pelo seu alto potencial produtivo. Todavia, apesar desse elevado potencial de produção, a espécie possui marcante estacionalidade na produção, em geral, $70 \%$ no período das águas.

A baixa produção de forrageiras tropicais no inverno é atribuída, segundo Ferreira (1998), à deficiência hídrica, ao fotoperíodo mais curto e às baixas temperaturas noturnas no inverno. Segundo Whitheman (1980), as espécies de clima tropical produzem muito pouco, quando expostas a temperaturas menores que $16^{\circ} \mathrm{C}$. Segundo Corsi et al. (1998), a falta de água impõe limitações sobre a taxa de expansão de folhas, o número de folhas por perfilho e o número de perfilhos. Por esta razão, na seca, é necessário que se adote manejo diferenciado para manter a produtividade obtida no período das águas.

A irrigação de pastagens, principalmente em regiões onde as temperaturas de inverno não são limitantes do crescimento das plantas, é uma alternativa viável, por apresentar bons resultados quanto à escassez de alimento no período seco. De acordo com Alencar (2001) os resultados obtidos nestas regiões (taxas de lotação próximas de 10 UA/ha e ganhos de peso vivo na faixa de 1 quilo/ dia, inclusive durante o período seco) têm demonstrado nova possibilidade de manejo para manutenção da produtividade.

Ondei (1999) afirma que a prática da irrigação de pastagem tem proporcionado taxas de lotação de até 6 UA/ha contra a média local de 0,3 a 0,5 UA/ha. Vale ressaltar que as temperaturas mais elevadas na região de Governador Valadares durante o período seco contribuíram para a diminuição da estacionalidade da produção.

Segundo Alencar (2001), pastagens adubadas e irrigadas têm potencial para altas taxas de lotação nos trópicos (entre 6,0 e 9,9 UA/ha). Além disso, o aumento dos custos com produção de matéria seca, utilizando-se um sistema de irrigação de baixa pressão, de US\$0,02/kg de MS para US\$ 0,03/kg de MS, incentiva a adoção desta prática.

No entanto, a irrigação de pastagens, baseada nas premissas de eliminar a estacionalidade da produção e produzir maior quantidade de massa seca durante o ano, mostra-se menos eficiente que a primeira, principalmente em regiões com invernos onde a temperatura média mínima fica abaixo de $16^{\circ} \mathrm{C}$ e há baixa intensidade luminosa, pelo menos não a ponto de igualar a produção de inverno à de verão.

Entretanto, conforme Corsi \& Martha Jr. (1998), é possível manter em pastagens irrigadas, no período de outono-inverno, taxa de lotação animal de 40 a $60 \%$ daquela mantida na primavera-verão. Esse índices são considerados bons, se comparados àqueles obtidos em pastagens não-irrigadas (10 a $20 \%$ da taxa de lotação obtida no período das chuvas em pastagens manejadas intensivamente).

Drumond \& Fernandes (2001) afirmam a existência de áreas irrigadas por pivô central recémimplantadas, com taxa de lotação de $10 \mathrm{UA} /$ ha na primavera-verão e de $6 \mathrm{UA} / \mathrm{ha}$ no outono-inverno e ganhos médios de 800 g/UA/dia. Em pastagens nãoirrigadas, a taxa de lotação é de $8 \mathrm{UA} /$ ha na primavera-verão é de 1,0 a 1,5 UA/ha no outono-inverno. Portanto, mesmo sem manter a produtividade do verão, a irrigação de pastagens pode apresentar como alternativa para o "período de seca", desde que haja uma avaliação dos custos e das características de temperatura de inverno da região.

Os resultados obtidos com o incremento de produção de massa seca durante o ano têm sido mais animadores, corroborando a expectativa de Guelfi Filho (1972), que, irrigando o capim-elefante durante o verão, obteve aumento na produção de massa seca de $3.590 \mathrm{~kg}$ de MS/ha em relação à testemunha, enquanto os aumentos no inverno foram de $1.189 \mathrm{~kg}$ de MS/ha. Este aumento de produção é decorrente da solução do problema da ocorrência de veranicos. Assim, sem as flutuações na produção, o sistema torna-se mais estável. O manejo resume-se em adaptar a adubação à pressão de pastejo, características peculiares de cada propriedade. Segundo Aguiar (2001), a melhor resposta da irrigação em pastagens ocorre no verão, quando a temperatura e luminosidade são altas, possibilitando aumentos de 20 a $30 \%$ na produção de forragem.

R. Bras. Zootec., v.34, n.1, p.20-29, 2005 
Maior disponibilidade deve ser ajustada com aumento do número de pastejos sobre a mesma área, porque, com a aceleração do desenvolvimento da planta forrageira sob estas condições, há possibilidade de rápido desenvolvimento fisiológico da planta, o que acarreta a possibilidade de quedas nos teores de proteína bruta e elevação nos de fibra detergente neutro (FDN) e fibra detergente ácido (FDA), prejudicando o consumo dos animais e reduzindo o ganho por animal. Fulkerson \& Slack (1995) afirmam que o número de folhas vivas/perfilho é definido pela espécie, mas podese inferir que as plantas recebendo $\mathrm{N}$ e irrigação irão atingir o número máximo de folhas vivas/perfilho mais precocemente, promovendo, com isso, a possibilidade de desfolhações mais freqüentes, a fim de evitar perdas por senescência foliar e também em valor nutritivo.

Maraschin (2000), com base no fato de o animal selecionar, preferencialmente, lâmina foliar, afirma que a oferta de forragem não deve se fundamentar em massa verde seca, e sim em massa seca de lâmina foliar. Além disso, Alexandrino et al. (2000) afirmam que a lâmina foliar, além de se relacionar com a produção de massa seca total da planta, apresenta duas funções dentro do contexto de pastagem: representa parte substancial do tecido fotossintético ativo e da área foliar que garante a produção de fotoassimilados da planta, além de constituir-se em um material de alto valor nutritivo para os ruminantes

Assim, fica evidente que a massa seca de lâminas foliares verdes deve ser considerada, avaliada e oferecida ao animal em pastejo, pois, a partir do entendimento deste componente da planta, poder-se-á definir a característica da forragem em pastagens de qualidade e estabelecer, com propriedade, a relação planta-animal (Maraschin, 2000). Dessa maneira, com o objetivo de avaliar a disponibilidade de massa seca de lâminas foliares e sua composição bromatológica, frente às práticas de irrigação e adubação, conduziu-se este experimento.

\section{Material e Métodos}

O experimento foi conduzido no setor de Agrostologia do Departamento de Zootecnia da UFV, entre abril de 1999 a março de 2001. A temperatura média anual de Viçosa é de $19^{\circ} \mathrm{C}$. A umidade relativa do ar é, em média, de $80 \%$ e a precipitação média anual, de $1.341 \mathrm{~mm}$, com $20^{\circ} 45^{\prime} 25^{\prime \prime}$ de latitude sul, $42^{\circ} 51^{\prime} 11^{\prime \prime}$ de longitude oeste e altitude de $651 \mathrm{~m}$, bem como estações seca e chuvosa bem definidas. O clima é classificado como Cwa, subtropical, com inverno ameno e seco.

A correção da acidez do solo foi realizada com a aplicação 2,25 t/ha de calcário dolomítico, com PRNT de 63,7\%, segundo o método do $\mathrm{Al}, \mathrm{Ca}$ e $\mathrm{Mg}$ trocáveis (CFSEMG, 1999). O plantio do capim-elefante (Pennisetum purpureum, Schum.), cultivar Napier, foi realizado em sulcos espaçados de $0,5 \mathrm{~m}$, com adubação fosfatada (superfosfato simples) de 200 $\mathrm{kg} /$ ha de $\mathrm{P}_{2} \mathrm{O}_{5}$. No ano seguinte, a adubação fosfatada de manutenção foi de $40 \mathrm{~kg} / \mathrm{ha}$ de $\mathrm{P}_{2} \mathrm{O}_{5}$.

Os tratamentos consistiram da aplicação de quatro doses de nitrogênio e potássio, em uma relação $1 \mathrm{~N}: 0,8 \mathrm{~K}_{2} \mathrm{O}$, com e sem irrigação: $100 \mathrm{~kg} / \mathrm{ha}$ de nitrogênio $+80 \mathrm{~kg} / \mathrm{ha}$ de potássio; $200 \mathrm{~kg} / \mathrm{ha}$ de nitrogênio $+160 \mathrm{~kg} / \mathrm{ha}$ de potássio; $300 \mathrm{~kg} / \mathrm{ha}$ de nitrogênio + $240 \mathrm{~kg} / \mathrm{ha}$ de potássio; e $400 \mathrm{~kg} / \mathrm{ha}$ de nitrogênio $+320 \mathrm{~kg} /$ ha de potássio.

As adubações nitrogenadas (uréia) e potássicas (cloreto de potássio) foram realizadas em cobertura após o estabelecimento do capim, ao passo que as adubações de manutenção, de acordo com os tratamentos. Nos tratamentos de sequeiro, a quantidade correspondente a cada dose foi dividida em três partes iguais aplicadas no período das águas, enquanto nos irrigados $70 \%$ de sua adubação foram divididos em três partes iguais no período chuvoso e os $30 \%$ restantes, aplicados no período da seca.

O delineamento experimental foi o de blocos ao acaso com três repetições, para os tratamentos de sequeiro e irrigado, em que cada parcela (com ou sem irrigação) foi composta por três blocos de $1.200 \mathrm{~m}^{2}$ cada, divididos em quatro piquetes de $300 \mathrm{~m}^{2}$ (subparcela), constituindo a unidade experimental. O método de pastejo adotado foi o rotacionado, com entrada dos animais nos piquetes quando a média da altura da planta forrageira nos tratamentos atingisse $1,70 \mathrm{~m}$, aproximadamente. Os animais permaneceram nos piquetes até a altura residual média de $0,80 \mathrm{~m}$. Durante o período de descanso, os animais foram mantidos em outras áreas, não possibilitando, assim, a determinação de seus desempenhos.

A irrigação foi feita por meio de um sistema de aspersão convencional de média pressão. A linha principal do sistema era fixa, constituída por tubos de PVC de 3" com conexão rosqueável do tipo engate rápido. As linhas laterais, também de PVC de 2", com engate rápido, continham cinco aspersores, fornecendo vazão de $2,39 \mathrm{~m}^{3} / \mathrm{h}$. O espaçamento utilizado entre aspersores foi de $18 \times 18 \mathrm{~m}$.

\section{R. Bras. Zootec., v.34, n.1, p.20-29, 2005}


O manejo da irrigação foi feito com turno de rega variável, usando-se o método do tanque "Classe A" para estimativa da evapotranspiração de referência, por meio da equação $\left(\mathrm{ET}_{0}=\mathrm{Kt} \times \mathrm{EV}\right)$, em que: $\mathrm{ET}_{0}$ refere-se à evapotranspiração de referência, $\mathrm{mm} \mathrm{dia}^{-1} ; \mathrm{Kt}$, ao coeficiente do tanque, adimensional; e EV, à evaporação no tanque "Classe $\mathrm{A}$ ", mm dia ${ }^{-1}$.

A evapotranspiração potencial da cultura (ETpc, mm.dia ${ }^{-1}$ ) foi estimada aplicando-se a equação $\left(\mathrm{ETpc}=\mathrm{Kc}_{\mathrm{x} \mathrm{ET}}\right)$, em que Kc é coeficiente de cultura, adimensional. O valor do Kc $(0,85)$ foi definido para o estádio de desenvolvimento II (FAO), citado por Bernardo (1996).

A evapotranspiração real da cultura (ETrc, mm.dia $\left.{ }^{-1}\right)$ foi obtida pela equação $(\mathrm{ETrc}=\mathrm{Ks} \mathrm{x} \mathrm{ETpc})$, em que: Ks: coeficiente de umidade do solo, adimensional. O Ks foi estimado aplicando-se a equação (1) proposta por Bernardo (1996), em que: LAA: lâmina de água no solo, mm; e CTA: capacidade total de retenção de água no solo, $\mathrm{mm}$.

$$
\mathrm{Ks}=\frac{\ln (L A A+1,0)}{\ln (C T A+1,0)}
$$

A CTA foi calculada por meio da equação (2), em que: Cc é capacidade de campo, \% em peso; Pm, ponto de murcha permanente, $\%$ em peso; Da, densidade do solo, $\mathrm{g} \mathrm{cm}^{-3}$; e Z, profundidade efetiva do sistema radicular da cultura, $\mathrm{cm}$.

$$
\mathrm{CTA}=\frac{(C c-P m)}{10} \times \mathrm{Da} \times \mathrm{Z}
$$

A Cc foi determinada por meio do método do equivalente de umidade e o Pm, utilizando-se o extrator de Richards. A Da foi determinada em amostras indeformadas, obtidas com amostrador tipo Uhland.

Dessa maneira, a irrigação foi efetuada quando o valor do somatório da evapotranspiração real da cultura, subtraído da precipitação efetiva, foi aproximadamente igual ao valor da capacidade real de água no solo (CRA, mm), que foi calculada aplicando-se a equação $($ CRA $=$ CTA $x$ f $)$, em que $f$ é fator de disponibilidade de água no solo, adimensional. No cálculo da CRA, considerou-se $\mathrm{f}=0,5$, para as condições de planta e clima envolvidas no experimento.

O tempo de duração de cada evento de irrigação foi calculado a partir da relação entre a irrigação total necessária (ITN) e a intensidade de aplicação de água dos aspersores. A ITN foi calculada por meio da equação (3), em que Pe refere-se à precipitação efetiva (mm) e Ea, à eficiência de aplicação de água do sistema de irrigação, decimal.

R. Bras. Zootec., v.34, n.1, p.20-29, 2005

$$
\mathrm{ITN}=\frac{\sum E \operatorname{Tr} c-P e}{E a}
$$

A Ea foi calculada aplicando-se a equação (4), em que: $\bar{H}$ élâmina média colhida (mm) e $H m$, lâmina média aplicada $(\mathrm{mm})$.

$$
\mathrm{Ea}=\frac{\bar{H}}{H m} \times 100
$$

A determinação da $\bar{H}$ foi obtida por intermédio de um conjunto de pluviômetros, em torno do aspersor central da linha de irrigação. A uniformidade de distribuição de água foi realizada por meio do cálculo do coeficiente de uniformidade de Christiansen (Bernardo, 1996).

A lâmina total de água aplicada na primeira irrigação foi calculada com base na umidade do solo, determinada por intermédio do método padrão de estufa, usando-se amostras representativas da camada de $30 \mathrm{~cm}$ de profundidade. Os dados de precipitação pluvial (1.169,10 mm/ano), evaporação (1.390,65 mm/ano), velocidade do vento, umidade relativa $(81,17 \%)$ e temperaturas médias $\left(19,7^{\circ} \mathrm{C}\right)$, mínimas $\left(14,8^{\circ} \mathrm{C}\right)$ e máximas $\left(26,7^{\circ} \mathrm{C}\right)$ foram obtidos na Estação Meteorológica Principal da Universidade Federal de Viçosa.

No primeiro ciclo de pastejo de cada estação, foram retiradas cinco amostras de forragem de cada piquete, utilizando-se um quadrado de $1 \mathrm{~m}$ de lado alocado sistematicamente. No interior do quadrado, foram medidas as alturas das plantas e estimado o percentual de cobertura do solo por dois observadores. Da forragem dentro do quadrado, colhida acima de $80 \mathrm{~cm}$ do solo, retirou-se uma amostra representativa, que foi separada em colmo + bainha e pseudocolmo + lâmina foliar e levadas para estufa a $65^{\circ} \mathrm{C}$, por 72 horas, para a obtenção da porcentagem de matéria seca. A partir deste ponto, as frações colmo + bainha e pseudocolmo + lâmina foliar serão referidas no texto somente como colmo e lâmina foliar, respectivamente.

De posse das informações obtidas dentro de cada quadrado, foram estabelecidas equações de regressão, em que a disponibilidade de massa seca foi considerada variável dependente e a altura e cobertura independentes. Dessa maneira, dentro da mesma estação, nos posteriores ciclos de pastejos, foram avaliadas somente medidas de altura e cobertura, em um total de dez amostras por piquete. Com base nas equações anteriores, estimou-se a disponibilidade de massa seca de lâminas foliares em cada tratamento. 
As características avaliadas no primeiro ano de avaliação foram altura média da planta forrageira, cobertura do solo, disponibilidade de massa seca de lâminas foliares e relação lâmina foliar/colmo. No segundo ano de avaliação, além das características anteriores, avaliaram-se os teores de FDN, de FDA e de proteína bruta nas lâminas foliares.

Os dados foram processados pelo Sistema de Análises Estatísticas e Genéticas-SAEG (UFV, 1993) e os tratamentos, comparados pelo teste Tukey, a 5\% de probabilidade.

\section{Resultados e Discussão}

Na Tabela 1, são apresentados apenas os resultados para os tratamentos irrigados no período seco (abril a setembro) do primeiro ano de avaliação. A falta dos resultados de sequeiro decorreu da ausência de crescimento da forrageira não-irrigada neste período, onde as alturas observadas foram equivalentes às do corte para amostragem no início das avaliações. Este fato ocorreu provavelmente devido às características climáticas de Viçosa nesta época, caracterizadas por baixas temperaturas e baixa precipitação pluvial. Além disso, a planta forrageira ainda estava em fase de estabelecimento, com raízes pouco desenvolvidas, o que pode ter contribuído para o comprometimento do crescimento das plantas na ausência da irrigação.

Em relação aos tratamentos sob irrigação, a expectativa de aumento significativo $(\mathrm{P}<0,05)$ das variáveis estudadas para cada aumento da adubação não se confirmou. Somente a maior dose mostrou-se significativamente maior, principalmente em relação à cobertura e MSLF. Por outro lado, para a relação $\mathrm{L} / \mathrm{C}$, não houve diferenças significativas $(\mathrm{P}>0,05)$ entre os tratamentos, demonstrando que não houve modificações na proporção destes dois componentes com o aumento das doses aplicadas.

A ausência de efeito significativo dos fertilizantes entre as características avaliadas indica que, apesar da irrigação, mesmo nas maiores doses de $\mathrm{N}$ e K aplicadas, o capim-elefante não expressou plenamente seu potencial, graças às baixas temperaturas no período, com médias das mínimas em torno de $12,2^{\circ} \mathrm{C}$. Além das baixas temperaturas, o aumento das horas de ausência de luz determinou o florescimento da planta forrageira e, conseqüentemente, a paralisação e, ou, redução de seu crescimento.

Bahmani et al. (2001), estudando a influência da adubação nitrogenada no desenvolvimento de perfilhos
Tabela 1 - Altura, cobertura, disponibilidade de massa seca de lâminas foliares (MSLF) e relação lâmina foliar/colmo (L/C) do capim-elefante sob irrigação nas doses de $\mathrm{N}$ e K aplicadas no período seco (abril a setembro de 1999)

Table 1 - Height, covering, availability dry matter of leaf lamina (DMLF) and leaf/blade ratio (L/C) of elephantgrass irrigated and fertilized with nitrogen and potassium levels in the dry season (April at September) of 1999

\begin{tabular}{lcccc}
\hline $\begin{array}{l}\mathrm{N}+\mathrm{K} \\
\left(\mathrm{kg} \mathrm{ha}^{-1}\right)\end{array}$ & $\begin{array}{c}\text { Altura } \\
\text { Height } \\
(\mathrm{m})\end{array}$ & $\begin{array}{c}\text { Cobert. } \\
\text { Cover } \\
(\%)\end{array}$ & $\begin{array}{c}\text { MSLF } \\
\text { DMLF } \\
\mathrm{kg} \mathrm{ha}^{-1}\end{array}$ & $\begin{array}{c}\text { Relação L/C } \\
\text { L/C ratio }\end{array}$ \\
\hline $400+320$ & $1,35 \mathrm{a}$ & $21,0 \mathrm{a}$ & $3.683 \mathrm{a}$ & $0,97 \mathrm{a}$ \\
$300+240$ & $1,32 \mathrm{ab}$ & $\begin{array}{c}14,8 \mathrm{ab} \\
2.497 \mathrm{ab}\end{array}$ & $0,87 \mathrm{a}$ \\
$200+160$ & $1,26 \mathrm{ab}$ & $\begin{array}{c}12,0 \mathrm{~b} \\
2.097 \mathrm{~b}\end{array}$ & $1,02 \mathrm{a}$ \\
$100+80$ & $1,16 \mathrm{~b}$ & $12,2 \mathrm{~b}$ & $1.670 \mathrm{~b}$ & $0,81 \mathrm{a}$ \\
\hline
\end{tabular}

Médias seguidas de mesma letra na coluna não diferem estatisticamente a $5 \%$ pelo teste Tukey.

Means followed by same letters in the column are not different $(P>.05)$ by Tukey test.

reprodutivos, afirmaram que a adubação antes do florescimento poderia favorecer a produção de perfilhos vegetativos, aumentando a produção de forragem e a persistência da pastagem. No entanto, no presente experimento, a adubação e a irrigação realizados neste período do ano pareceram acelerar o desenvolvimento fisiológico das plantas. Estes resultados indicam que uma espécie de clima tropical poderia responder diferentemente a este tipo de manejo. Dessa maneira, havendo condições ambientais e nutricionais mais apropriadas para as forrageiras tropicais no período de menor luminosidade, provavelmente o florescimento ocorrerá mais rapidamente.

Ao considerar os períodos seco e chuvoso do primeiro ano (abril/99 a março/00), verificou-se que, nos tratamentos sob irrigação, a adubação se mostrou significativa $(\mathrm{P}<0,05)$ sobretudo para a disponibilidade de MSLF e L/C, obtendo-se os maiores valores sempre para as maiores doses de nutrientes aplicadas (Tabela 2), à exceção da relação lâmina/colmo, que mostrou resultado inverso aos das outras características.

Este resultado indica o efeito da quantidade de adubo aplicado no rápido crescimento do capimelefante, que, por sua vez, se caracteriza por rápido alongamento do colmo em situações ótimas de crescimento. Este alongamento dos colmos provoca a elevação do meristema apical, colocando-o em posição de alta vulnerabilidade ao pastejo, além de provocar redução na relação lâmina/colmo, contribuindo para diminuição do valor nutritivo da planta forrageira 
(Andrade \& Gomide, 1971). Dentro desta expectativa, Gomide \& Gomide (2001), trabalhando com capimmombaça pastejado em lotação rotacionada, observaram correlação negativa entre o ganho diário de peso animal e a duração do período de descanso, demonstrando a importância da relação folha/colmo do relvado para o desempenho dos animais.

Para os tratamentos de sequeiro, a falta de diferença significativa $(\mathrm{P}>0,05)$ para a relação lâmina/ colmo evidencia a menor velocidade de crescimento do capim-elefante na ausência de irrigação e, conseqüentemente, o menor alongamento dos colmos e a manutenção da relação lâmina foliar/colmo em valores mais altos, possivelmente em virtude da falta de manutençãoda umidade no solo, decorrente dos veranicos.

$\mathrm{Na}$ avaliação dos efeitos da irrigação durante o primeiro ano (Tabela 2), a disponibilidade de lâminas foliares não apresentou aumento significativo, exceção apenas para o tratamento $200+160$. No entanto, as diferenças significativas observadas para a relação lâmina/colmo do capim-elefante evidenciaram o rápido alongamento do colmo, em detrimento ao aumento na disponibilidade de lâminas foliares. Estes resultados mostram que as elevadas doses de nutrientes, juntamente com a irrigação, aceleram o desenvolvimento da planta forrageira em condições apropriadas de luminosidade e temperatura. Assim, é importante que, ao trabalhar com capim-elefante nestas condições, se maneje a planta forrageira com mais frequiência, pois a espécie tende a desviar nutrientes para o alongamento dos colmos, mantendo a produção de lâmina estabilizada após certo período de crescimento. Isto evitaria rápido alongamento dos colmos, permitindo aos animais a seleção de forragem de melhor valor nutritivo.

Este fato pode ser comprovado por Euclides et al. (1999), em que o teor de PB e a digestibilidade in situ da matéria seca e FDN foram iguais para três cultivares de Panicum, no entanto, os animais pastejando capim-tanzânia apresentaram os maiores ganhos. Segundo os autores, o consumo voluntário de massa seca foi correlacionado $\left(\mathrm{P}<0,01, \mathrm{r}^{2}=0,77\right)$ com o ganho diário de peso, confirmando que, entre as características das plantas forrageiras, as de maior importância (disponibilidade de folhas, porcentagem de folha e relação material verde:material morto) são aquelas que determinam o consumo voluntário de nutrientes.

No período seco (abril a setembro) do ano de 2000, tanto a irrigação como a adubação determinaram diferenças $(\mathrm{P}<0,05)$ para a disponibilidade de massa seca de lâminas foliares e altura, principalmente para as menores doses aplicadas, à exceção dos resultados obtidos para a relação lâmina/colmo e cobertura, que não apresentaram diferença para efeito da irrigação (Tabela 3). Esta constatação contraria a expectativa de que há interação entre a irrigação e as maiores doses de $\mathrm{N}$ e $\mathrm{K}$ aplicadas; por conseqüência, as diferenças entre os tratamentos aumentariam com a dose aplicada.

Marcelino et al. (2003), trabalhando com cv. Tifton 85 e Brachiaria brizantha, também não verificaram efeitos significativos da irrigação no período de maio a agosto, em Brasília, provavelmente, em consequiência das baixas temperaturas e dos dias curtos no período, quando a temperatura mínima ficou abaixo de $15^{\circ} \mathrm{C}$.

Na avaliação do segundo ano (abril/2000 a março/ 2001), quando se considerou o período seco juntamente com o chuvoso, diferentemente dos resultados do período seco, as doses de $\mathrm{N}$ e $\mathrm{K}$ elevaram significativamente $(\mathrm{P}<0,05)$ os valores obtidos para altura, cobertura e MSLF, tanto para os tratamentos irrigados como para os de sequeiros (Tabela 3 ). Os valores da relação lâmina foliar/colmo, no entanto, não apresentaram diferenças significativas e, ao contrário das outras características avaliadas, mostraram tendência de queda com as maiores doses aplicadas.

Os valores extremamente baixos para a relação lâmina/colmo, obtidos principalmente para as maiores doses de adubo com irrigação, deixam claro, mais uma vez, a importância do estabelecimento de um manejo diferenciado para cada situação de adubação, sendo necessário aproveitar não somente a maior disponibilidade da forragem produzida, mas também a maior taxa de crescimento, ou seja, aumentar a freqüência de pastejo.

Características morfofisiológicas para se estipular o momento ideal de desfolhação, como interceptação luminosa de $95 \%$ e início do aumento na taxa de senescência foliar, têm sido utilizadas com algum sucesso (Sbrissia \& Silva, 2001). No entanto, segundo Parsons \& Penning (1988), a taxa média de crescimento é relativamente insensível à duração do período de rebrotação após um período mínimo de descanso, razão pela qual atenção deve ser voltada à estrutura do pasto, mais especificamente para a sua relação lâmina foliar/colmo. Por outro lado, no método de lotação rotacionada, com desfolhações severas (baixo IAF residual) em contraste com lotação contínua, não é eficiente em controlar o desenvolvimento dos

R. Bras. Zootec., v.34, n.1, p.20-29, 2005 
Tabela 2 - Altura, cobertura, disponibilidade de massa seca de lâminas foliares (MSLF) e relação lâmina foliar/colmo (L/C) do capim-elefante submetido a doses de nitrogênio e de potássio, com irrigação (Irrig.) e sequeiro (Seq.) no primeiro ano (abril/99 a março/00)

Table 2 - Height, covering, dry matter availability of leaf lamina (DMLF) and leaf/blade ratio of elephantgrass fertilized with nitrogen and potassium levels with irrigation (IR.) and no irrigated (NI) at first year (April/99 to Marth/00)

\begin{tabular}{|c|c|c|c|c|c|c|c|c|}
\hline \multirow[t]{2}{*}{$\begin{array}{l}\mathrm{N}+\mathrm{K} \\
\left(\mathrm{kg} \mathrm{ha}^{-1}\right)\end{array}$} & \multicolumn{2}{|c|}{$\begin{array}{c}\text { Altura }(\mathrm{m}) \\
\text { Height }\end{array}$} & \multicolumn{2}{|c|}{$\begin{array}{l}\text { Cobertura }(\%) \\
\text { Covering }\end{array}$} & \multicolumn{2}{|c|}{$\begin{array}{c}\text { MSLF }\left(\mathrm{kg} \mathrm{ha}^{-1}\right) \\
D M L F\end{array}$} & \multicolumn{2}{|c|}{$\begin{array}{l}\text { Relação Ratio } \\
\text { L/C } L / C\end{array}$} \\
\hline & Irrig. (IR) & Seq. (NI) & Irrig. (IR) & Seq. (NI) & Irrig. (IR) & Seq. (NI) & Irrig. (IR) & Seq. (NI) \\
\hline $400+320$ & $1,70 \mathrm{aA}$ & $1,78 \mathrm{aA}$ & $18,4 \mathrm{aA}$ & $15,8 \mathrm{aA}$ & $17.257 \mathrm{aA}$ & $16.503 \mathrm{aA}$ & $0,60 \mathrm{cB}$ & $0,90 \mathrm{aA}$ \\
\hline $300+240$ & $1,59 \mathrm{abB}$ & $1,74 \mathrm{aA}$ & $16,7 \mathrm{abA}$ & $13,1 \mathrm{aB}$ & $16.490 \mathrm{aA}$ & $15.263 \mathrm{aA}$ & $0,71 \mathrm{bB}$ & $1,00 \mathrm{aA}$ \\
\hline $200+160$ & $1,58 \mathrm{abA}$ & $1,68 \mathrm{abA}$ & $15,1 \mathrm{abA}$ & $12,0 \mathrm{aA}$ & $13.817 \mathrm{bA}$ & $11.347 \mathrm{aB}$ & $0,70 \mathrm{bcB}$ & $0,95 \mathrm{aA}$ \\
\hline $100+80$ & $1,45 \mathrm{bB}$ & $1,59 \mathrm{bA}$ & $12,8 \mathrm{bA}$ & $11,8 \mathrm{aA}$ & $11.550 \mathrm{bA}$ & $11.997 \mathrm{aA}$ & $0,93 \mathrm{aA}$ & $1,00 \mathrm{aA}$ \\
\hline
\end{tabular}

Médias seguidas de mesmas letras minúsculas na coluna não diferem estatisticamente a $5 \%$ pelo teste Tukey.

Médias seguidas de mesmas letras maiúsculas na linha, para cada característica, não diferem estatisticamente a $5 \%$ pelo teste Tukey. Means followed by same letters minuscule in the column are not different $(P>.05)$ by Tukey test.

Means followed bu same letters capital in the line, for each characteristic, are not different $(P>.05)$ by Tukey test.

Tabela 3 - Altura, cobertura, disponibilidade de massa seca de lâminas foliares (MSLF) e relação lâmina foliar/colmo (L/C) do capim-elefante submetido a doses de nitrogênio e de potássio com irrigação (Irrig.) e sequeiro (Seq.), no período seco (abril a setembro) de 2000 e no segundo ano de experimento (abril/2000 a março/2001)

Table 3 - Height, covering, dry matter availability of leaf blade(DMLF) and lamina/culm ratio of elephantgrass fertilized with nitrogen and potassium levels with irrigation (IR.) and no irrigated (NI) at dry season (April to September of 2000) and in the second year (April/2000 to March/2001)

\begin{tabular}{|c|c|c|c|c|c|c|c|c|}
\hline \multicolumn{9}{|c|}{$\begin{array}{l}\text { Período seco (abril a setembro) de } 2000 \\
\text { Dry season (April to September of 2000) }\end{array}$} \\
\hline \multirow[t]{2}{*}{$\begin{array}{l}\mathrm{N}+\mathrm{K} \\
\left(\mathrm{kg} \mathrm{ha}^{-1}\right)\end{array}$} & \multicolumn{2}{|c|}{$\begin{array}{c}\text { Altura }(\mathrm{m}) \\
\text { Height }\end{array}$} & \multicolumn{2}{|c|}{$\begin{array}{c}\text { Cobertura }(\%) \\
\text { Covering }\end{array}$} & \multicolumn{2}{|c|}{$\begin{array}{c}\operatorname{MSLF}\left(\mathrm{kg} \mathrm{ha}^{-1}\right) \\
D M L F\end{array}$} & \multicolumn{2}{|c|}{$\begin{array}{c}\text { Relação } \mathrm{L} / \mathrm{C} \\
\text { L/C ratio }\end{array}$} \\
\hline & Irrig. (IR) & Seq. $(N I)$ & Irrig. (IR) & Seq. $(N I)$ & Irrig. (IR) & Seq. $(N I)$ & Irrig. (IR) & Seq. $(N I)$ \\
\hline $400+320$ & $1,57 \mathrm{aA}$ & $1,47 \mathrm{aA}$ & $16,8 \mathrm{aA}$ & $16,3 \mathrm{aA}$ & $3.855 \mathrm{aA}$ & $3.315 \mathrm{aA}$ & $0,62 \mathrm{aA}$ & $0,61 \mathrm{aA}$ \\
\hline $300+240$ & $1,60 \mathrm{aA}$ & $1,38 \mathrm{aB}$ & $15,2 \mathrm{abA}$ & $14,3 \mathrm{aA}$ & $3.565 \mathrm{aA}$ & $3.105 \mathrm{aA}$ & $0,63 \mathrm{aA}$ & $0,48 \mathrm{aA}$ \\
\hline $200+160$ & $1,47 \mathrm{abA}$ & $1,43 \mathrm{aA}$ & $14,5 \mathrm{abA}$ & $11,0 \mathrm{abA}$ & $3.147 \mathrm{abA}$ & $2.217 \mathrm{bB}$ & $0,71 \mathrm{aA}$ & $0,62 \mathrm{aA}$ \\
\hline $100+80$ & $1,35 \mathrm{bA}$ & $1,19 \mathrm{bB}$ & $10,7 \mathrm{bA}$ & $8,5 \mathrm{bA}$ & $2.690 \mathrm{bA}$ & $1.799 \mathrm{bB}$ & $0,66 \mathrm{aA}$ & $0,73 \mathrm{aA}$ \\
\hline \multicolumn{9}{|c|}{$\begin{array}{l}\text { Segundo ano de experimento (abril/2000 a março/2001) } \\
\text { Second year of experiment (April/2000 to Marth/2001) }\end{array}$} \\
\hline \multirow[t]{2}{*}{$\begin{array}{l}\mathrm{N}+\mathrm{K} \\
\left(\mathrm{kg} \mathrm{ha}^{-1}\right)\end{array}$} & \multicolumn{2}{|c|}{$\begin{array}{c}\text { Altura }(\mathrm{m}) \\
\text { Height }\end{array}$} & \multicolumn{2}{|c|}{$\begin{array}{c}\text { Cobertura }(\%) \\
\text { Covering } \\
\end{array}$} & \multicolumn{2}{|c|}{$\begin{array}{c}\text { MSLF }\left(\mathrm{kg} \mathrm{ha}^{-1}\right) \\
D M L F\end{array}$} & \multicolumn{2}{|c|}{$\begin{array}{c}\text { Relação L/C } \\
\text { L/C ratio }\end{array}$} \\
\hline & Irrig. (IR) & Seq. $(N I)$ & Irrig. (IR) & Seq. $(N I)$ & Irrig. (IR) & Seq. $(N I)$ & Irrig. (IR) & Seq. $(N I)$ \\
\hline $400+320$ & $1,83 \mathrm{aA}$ & $1,84 \mathrm{aA}$ & $16,9 \mathrm{aA}$ & $17,3 \mathrm{aA}$ & $25.989 \mathrm{aA}$ & $23.295 \mathrm{aA}$ & $0,34 \mathrm{aB}$ & $0,45 \mathrm{aA}$ \\
\hline $300+240$ & $1,76 \mathrm{abA}$ & $1,76 \mathrm{abA}$ & $15,3 \mathrm{abA}$ & $16,0 \mathrm{abA}$ & $23.358 \mathrm{aA}$ & $20.362 \mathrm{aB}$ & $0,39 \mathrm{aA}$ & $0,41 \mathrm{aA}$ \\
\hline $200+160$ & $1,69 \mathrm{bA}$ & $1,71 \mathrm{bA}$ & $13,5 \mathrm{bA}$ & $13,5 \mathrm{bA}$ & $18.221 \mathrm{bA}$ & $12.663 \mathrm{bB}$ & $0,41 \mathrm{aA}$ & $0,41 \mathrm{aA}$ \\
\hline $100+80$ & $1,67 \mathrm{bA}$ & $1,59 \mathrm{cB}$ & $12,0 \mathrm{bA}$ & $13,1 \mathrm{bA}$ & $14.294 \mathrm{cA}$ & $13.079 \mathrm{bA}$ & $0,43 \mathrm{aA}$ & $0,47 \mathrm{aA}$ \\
\hline
\end{tabular}

Médias seguidas de mesmas letras minúsculas na coluna não diferem estatisticamente a $5 \%$ pelo teste Tukey.

Médias seguidas de mesmas letras maiúsculas na linha, para cada característica, não diferem estatisticamente a $5 \%$ pelo teste Tukey. Means followed by same small letters in the column are not different $(P>.05)$ by Tukey test.

Means followed bu same capital letters in the line, for each characteristic, are not different $(P>.05)$ by Tukey test.

colmos, principalmente quando o período de rebrotação é muito longo. Os colmos, além de dificultarem a apreensão da forragem pelos animais e terem menor valor nutritivo, também, em longos períodos de rebrotação, a densidade populacional de perfilhos pode reduzir, prejudicando a rebrotação subseqüente na pastagem (Tainton, 1974; Smetham, 1975, citados por Sbrissia \& Silva, 2001).
O aumento na MSLF acumulada ao longo do ano, pode ter sido resultado das temperaturas mais elevadas no mês de setembro, quando a temperatura média mínima ficou acima dos $15^{\circ} \mathrm{C}$, como também da eficiência da irrigação para compensar a desuniformidade de precipitação.

Quando se avaliou o efeito das doses de $\mathrm{Ne}$ K nos teores de PB, de FDN e de FDA para os tratamentos

\section{R. Bras. Zootec., v.34, n.1, p.20-29, 2005}


irrigados e de sequeiro no período seco, foram observadas diferenças $(\mathrm{P}<0,05)$ somente entre os tratamentos sem irrigação para PB e FDA (Tabela 4). A menor taxa de crescimento da planta forrageira e o efeito residual das maiores adubações no período chuvoso anterior nos tratamentos não irrigados, provavelmente, interferiram na idade fisiológica das lâminas foliares.

Quanto aos teores de FDN, a observância de diferenças significativas $(\mathrm{P}<0,05)$ para efeito da irrig ação em somente um nível de adubação, poderia indicar que a prática da irrigação não afetaria o consumo pelos animais. Isto porque, segundo Mertens (1994), a FDN pode ser usada para predição do consumo, uma vez que está inversamente relacionada ao conteúdo energético dos alimentos e melhor representa a propriedade dos alimentos em ocupar espaço.

Quanto à composição bromatológica, a irrigação provocou queda significativa $(\mathrm{P}<0,05)$ nos teores de PB das lâminas foliares com as maiores doses aplicadas, devido provavelmente ao rápido desenvolvimento fisiológico das folhas, o que determinou significativos $(\mathrm{P}<0,05)$ aumentos nos teores de FDN e de FDA (Tabela 5). Esta tendência está em consonância com as afirmações de Botrel et al. (1991) de que, sob condições climáticas favoráveis, o teor médio de PB das pastagens irrigadas pode reduzir em até $30 \%$, quando comparado ao das não-irrigadas, associando que as mais altas taxas de crescimento observadas sob condições irrigadas promovem diluição dos compostos protéicos na forragem produzida. Rego et al. (2001), trabalhando com capim-tanzânia, também observaram que incrementos na altura do pasto pro- moveram redução no teor de $\mathrm{PB}$ e aumentos nos teores de FDA e de FDN de lâminas foliares.

Esta falta de resposta à irrigação dentro do período de inverno deixa claro como a irrigação tem pequena influência no crescimento da planta forrageira e na disponibilidade de lâminas foliares, quando temperaturas e luminosidades ficam abaixo dos limites favoráveis ao pleno desenvolvimento da espécie.

Comparando os resultados do primeiro e segundo anos de avaliação (Tabelas 2 e 3), observa-se que o incremento na disponibilidade de MSLF no segundo ano foi sensivelmente maior em relação ao primeiro, fato ocorrido principalmente nas maiores doses de fertilizantes. No entanto, para a relação lâmina/colmo, obtiveram-se valores bem mais baixos no segundo ano de experimento. Segundo Veiga et al. (1985), em condições de pastejo, alta disponibilidade de forragem, sem manejo para manter a qualidade, pode ser contraprodutiva, o que ocorre quando maior produção de massa seca, com o incremento da adubação e/ou implementação da irrigação, pode resultar em maior proporção de colmos e acúmulo de material morto.

Os dados de cobertura do solo realçam os efeitos desta característica de desenvolvimento do capimelefante, onde, mesmo com as maiores doses aplicadas, a cobertura do solo não foi alterada. Os dados de altura, por sua vez, apresentaram pequeno aumento, evidenciando a prioridade no ganho em colmos. Segundo Bullock (1996), quando há rápido crescimento, em virtude da grande quantidade de adubo aplicado, os perfilhos tornam-se grandes para atingir o topo do dossel e captar a luz incidente e, portanto, a relação lâmina/colmo apresenta sensível queda, com forte alocação de carbono em estruturas de sustentação.

Tabela 4 - Proteína bruta (PB), fibra em detergente neutro (FDN) e fibra em detergente ácido (FDA) em lâminas foliares de capim-elefante, nas doses de $\mathrm{N}$ e K, com irrigação (Irrig.) e sequeiro (Seq.), no período seco (abril a setembro) de 2000

Table 4 - Contents of crude protein (CP), neutral detergent fiber (NDF) and acid detergent fiber (ADF) in the leaf lamina of elephantgrass fertilized with $N$ and K levels, with irrigation (IR.) and no irrigation (NI) in the dry season (April to September of 2000

\begin{tabular}{|c|c|c|c|c|c|c|}
\hline \multirow[t]{2}{*}{$\begin{array}{l}\mathrm{N}+\mathrm{K} \\
\left(\mathrm{kg} \mathrm{ha}^{-1}\right)\end{array}$} & \multicolumn{2}{|c|}{$\begin{array}{c}\mathrm{PB}(\%) \\
C P\end{array}$} & \multicolumn{2}{|c|}{$\begin{array}{c}\mathrm{FDN}(\%) \\
N D F\end{array}$} & \multicolumn{2}{|c|}{$\begin{array}{c}\mathrm{FDA}(\%) \\
A D F\end{array}$} \\
\hline & Irrig. (IR.) & Seq. $(N I)$ & Irrig.(IR.) & Seq. (NI) & Irrig.(IR.) & Seq. (NI) \\
\hline $400+320$ & $16,5 \mathrm{aA}$ & $15,7 \mathrm{aA}$ & $67,5 \mathrm{aA}$ & $67,6 \mathrm{aA}$ & $33,2 \mathrm{aA}$ & $33,3 \mathrm{bA}$ \\
\hline $300+240$ & $14,8 \mathrm{aA}$ & $15,5 \mathrm{abA}$ & $68,9 \mathrm{aA}$ & $69,2 \mathrm{aA}$ & $34,7 \mathrm{aA}$ & $34,2 \mathrm{abA}$ \\
\hline $200+160$ & $14,1 \mathrm{aA}$ & $13,0 \mathrm{bcA}$ & $68,7 \mathrm{aA}$ & $70,7 \mathrm{aA}$ & $33,8 \mathrm{aB}$ & $35,7 \mathrm{aA}$ \\
\hline $100+80$ & $14,2 \mathrm{aA}$ & $13,7 \mathrm{cA}$ & $66,3 \mathrm{aB}$ & $70,0 \mathrm{aA}$ & $33,3 \mathrm{aA}$ & $34,0 \mathrm{abA}$ \\
\hline
\end{tabular}

Médias seguidas de mesmas letras minúsculas na coluna não diferem estatisticamente a $5 \%$ pelo teste Tukey.

Médias seguidas de mesmas letras maiúsculas na linha, para cada característica, não diferem estatisticamente a 5\% pelo teste Tukey. Means followed by same letters minuscule in the column are not different $(P>.05)$ by Tukey test.

Means followed by same letters capital in the line, for each characteristic, are not different $(P>.05)$ by Tukey test.

R. Bras. Zootec., v.34, n.1, p.20-29, 2005 
Tabela 5 - Proteína bruta (PB), fibra em detergente neutro (FDN) e fibra em detergente ácido (FDA) em lâminas foliares de capim-elefante, nas doses de N e K, com irrigação (Irrig.) e sequeiro (Seq.), no segundo ano de experimento (abril/2000 a março/2001)

Table 5 - Contents of crude protein (CP), neutral detergent fiber (NDF) and acid detergent fiber (ADF) in the leaf lamina of elephantgrass at fertilized with $N$ and $K$ levels with irrigation (IR.) and no irrigated (NI) at dry season (April/2000 to September 2001)

\begin{tabular}{|c|c|c|c|c|c|c|}
\hline \multirow[t]{2}{*}{$\begin{array}{l}\mathrm{N}+\mathrm{K} \\
\left(\mathrm{kg} \mathrm{ha}^{-1}\right)\end{array}$} & \multicolumn{2}{|c|}{$\begin{array}{c}\mathrm{PB}(\%) \\
C P\end{array}$} & \multicolumn{2}{|c|}{$\begin{array}{c}\mathrm{FDN}(\%) \\
N D F\end{array}$} & \multicolumn{2}{|c|}{$\begin{array}{c}\mathrm{FDA}(\%) \\
A D F\end{array}$} \\
\hline & Irrig. (IR.) & Seq. $(N I)$ & Irrig.(IR.) & Seq. $(N I)$ & Irrig. (IR.) & Seq. $(N I)$ \\
\hline $400+360$ & $21,8 \mathrm{aB}$ & $23,5 \mathrm{aA}$ & $66,9 \mathrm{aA}$ & $64,7 \mathrm{aB}$ & $33,8 \mathrm{bA}$ & $31,9 \mathrm{bB}$ \\
\hline $300+240$ & $19,8 \mathrm{bB}$ & $22,5 \mathrm{aA}$ & $67,6 \mathrm{aA}$ & $64,5 \mathrm{aB}$ & $34,2 \mathrm{abA}$ & $32,1 \mathrm{bB}$ \\
\hline $200+160$ & $18,3 \mathrm{bcA}$ & $19,3 \mathrm{bA}$ & $68,8 \mathrm{aA}$ & $66,5 \mathrm{aB}$ & $34,8 \mathrm{aA}$ & $33,5 \mathrm{aB}$ \\
\hline $100+80$ & $17,3 \mathrm{cA}$ & $18,3 \mathrm{bA}$ & $67,2 \mathrm{aA}$ & $65,8 \mathrm{aA}$ & $34,2 \mathrm{abA}$ & $32,9 \mathrm{abB}$ \\
\hline
\end{tabular}

Médias seguidas de mesmas letras minúsculas na coluna não diferem estatisticamente a $5 \%$ pelo teste Tukey.

Médias seguidas de mesmas letras maiúsculas na linha, para cada característica avaliada, não diferem estatisticamente a $5 \%$ pelo teste Tukey.

Means followed by same letters minuscule in the column are not different $(P>.05)$ by Tukey test.

Means followed by same letters capital in the line, for each characteristic, are not different $(P>.05)$ by Tukey test.

O dinamismo da população de perfilhos, conseqüência da variação do tipo e origem de perfilhos predominantes, indica a necessidade potencial de se considerar a adoção de alturas ou intensidades de pastejo ou desfolhação variáveis e dependentes do estádio de desenvolvimento da planta ao longo do ano, sob pena de que alturas pré-determinadas e fixas possam vir a prejudicar a formação e renovação de perfilhos em determinada época do ano, gerando, conseqüentemente, redução da densidade populacional e da capacidade de rebrotação da planta forrageira (Silva et al., 1998). Além disso, esses autores revelaram que, para a mesma altura residual ou massa de forragem ( $\mathrm{kg} \mathrm{MS} / \mathrm{ha}$ ), mantida constante ao longo do ano, a estrutura do pasto pode ser alterada de forma drástica (composição botânica, densidade etc), fato que tem impacto direto sobre o animal que desfolha a planta, interferindo, potencialmente, na quantidade e qualidade de forragem consumida.

\section{Conclusões}

O uso da irrigação em pastagens de capim-elefante nos períodos de seca, mesmo com adubação, não foi efetivo para aumento da produção de massa seca de lâminas foliares, sobretudo para as maiores doses de adubo aplicado, onde existia a expectativa das maiores diferenças em relação às pastagens de sequeiro.

$\mathrm{Na}$ avaliação dos resultados do ano todo, o manejo da irrigação proporcionou maior disponibilidade de massa seca de lâminas foliares para alguns tratamentos, permitindo a inferência de que a opção de adoção desta prática em regiões como a do local deste experimento, deve visar o aumento da produção por hectare/ano, e não ter a expectativa de resolver a sazonalidade de produção.

Queda nos valores obtidos para a relação lâmina/ colmo e PB e elevação dos teores de FDN e de FDA, utilizando-se maiores doses de adubo e da irrigação, indicam a necessidade de modificação da frequiência de pastejo, principalmente para o período das águas, quando, juntamente com os fatores ambientais favoráveis, a irrigaçãopermite o rápidocrescimento da plantaforrageira.

\section{Literatura Citada}

AGUIAR, A.P. Manejo de pastagens. Capturado em: http:// www.cpt.com.br/revista/mattec/0190. asp 07/10/2001

ALENCAR, C.A.B. Pastagem e cana-de-açúcar, irrigados por aspersão de baixa pressão. SIMPÓSIO DE PRODUÇÃO DE GADO DE CORTE, 2., 2001, Viçosa, MG. Anais... Viçosa, MG: 2001. p.233-242.

ALEXANDRINO, E.; NASCIMENTO JR., D.; MOSQUIM, P.R. et al. Efeito de três doses de nitrogênio sobre características da Brachiaria brizantha cv. Marandu após o corte de uniformização. In: REUNIÃO ANUAL DA SOCIEDADE BRASILEIRA DE ZOOTECNIA, 37., 2000, Viçosa, MG. Anais... Viçosa, MG: Sociedade Brasileira de Zootecnia, 2000. CD-ROM. Forragicultura.

ANDRADE, I.F.; GOMIDE, J.A. Curva de crescimento e valor nutritivo do capim-elefante (Pennisetum purpureum, Schum) “A-146 Taiwan". Revista Ceres, v.8, n.100, p.431-447, 1971.

BAHMANI, E.R.; THOM, C.; MATTHEW, C. et al. Effect of nitrogen fertilizer on reproductive tiller development in perennial ryegrass. In: INTERNATIONAL GRASSLAND CONGRESS, 19., 2001, Piracicaba. Proceedings... Piracicaba: Fundação de Estudos Agrários Luiz de Queiroz, 2001. p.39-40.

BERNARDO, S. Manual de irrigação. 6.ed. Viçosa, MG: Universidade Federal de Viçosa, 1996. 657p.

BOTREL, M.A.; ALVIM, M.J.; XAVIER, D.F. Efeito da irrigação sobre algumas características agronômicas de cultivares de capim-elefante. Pesquisa Agropecuária Brasileira, v.26, n.10, p.1731-1736, 1991. 
BULLOCK, J.M. Plant competition and population dynamics. In: HODGSON, J.; ILLIUS, A.W. (Eds.). The ecology and management of grazing systems. Wallingford: $\mathrm{CAB}$ International, 1996. p.69-100.

CARDOSO, G.C. Alguns fatores práticos da irrigação de pastagens. In: SIMPÓSIO DE PRODUÇÃO DE GADO DE CORTE, 2., 2001, Viçosa, MG. Anais... Viçosa, MG: Universidade Federal de Viçosa, 2001. p.243-260.

COMISSÃO DE FERTILIDADE DO SOLO DO ESTADO DE MINAS GERAIS - CFSEMG. Recomendação para o uso de corretivos e fertilizantes em Minas Gerais. 5a aproximação. Viçosa, MG, 1999. 176p.

CORSI, M.; MARTHA JR., G.B. Manejo de pastagens para produção de carne e leite. In: SIMPÓSIO SOBRE MANEJO DE PASTAGENS, 15., 1998, Piracicaba. Anais... Piracicaba: Fundação de Estudos Agrários Luiz de Queiroz, 1998. p.55-84.

CORSI, M.; SILVA, S.C.; FARIA, V.P. Princípios de manejo do capim-elefante sob pastejo. Informe Agropecuário, v.19, n.192, p.36-43, 1998.

DRUMOND, L.C.D.; FERNANDES, A.L.T. Viabilidade econômica de irrigação de pastagem. Revista ABCZ, Ano 0, n.1, Abril/2001.

EUCLIDES, V.P.B.; THIAGO, L.R.L.; MARCELO, M.C.M. et al. Consumo voluntário de forragem de três cultivares de Panicum maximum sob pastejo. Revista Brasileira de Zootecnia, v.28, n.6, p.1177-1185, 1999.

FERREIRA, J.J. Alternativas de suplementação e valor nutritivo do capim-elefante sob pastejo rotacionado. Informe Agropecuário, v.19, n.192, p.66-72, 1998.

FNP CONSULTORIA E COMÉRCIO. Anuário estatístico da pecuária de corte. São Paulo: FNP, v.6, 1998.

FULKERSON, W.J.; SLACK, K. Leaf number as a criterion for determining defoliation time for Lolium perenne. 2. Effect of defoliation frequency and height. Grass and Forage Science, v.50, n.1, p.16-20, 1995.

GOMIDE, J.A.; GOMIDE, C.A.M. Utilização e manejo de pastagens. In: REUNIÃO ANUAL DA SOCIEDADE BRASILEIRA DE ZOOTECNIA, 38., 2001, Piracicaba. Anais... Piracicaba: 2001. CD-ROM. Forragicultura.

GUELFI FILHO, H. Efeito da irrigação sobre a produtividade do capim-elefante (Pennisetum purpureum Schum.) variedade napier. Piracicaba:Escola Superior de Agricultura Luiz de Queiroz, 1972. 77p. Tese (Doutorado em Zootecnia). Escola Superior de Agricultura Luiz de Queiroz, 1972.

MARASCHIN, G.E. Relembrando o passado, entendendo o presente e planejando o futuro uma herança em forrageiras e um legado em pastagens. In: REUNIÃO ANUAL DA SOCIEDADE BRASILEIRA DE ZOOTECNIA, 37., 2000, Viçosa, MG. Anais... Viçosa, MG: Sociedade Brasileira de Zootecnia, 2000. CD-ROM.
MARCELINO, K.R.A.; VILELA, L.; LEITE, G.G. et al. Manejo da adubação nitrogenada de tensões hídricas sobre a produção de matéria seca e índice de área foliar de Tifton 85 cultivado no Cerrado. Revista Brasileira de Zootecnia, v.32, n.2, p.268-275, 2003.

MERTENS, D.R. Regulation of forage intake. In: FAHEY JR., G.C. (Ed.) Forage quality, evaluation and utilization. Winsconsin: American Society of Agronomy, 1994. p.450-493.

NABINGER, C. Princípios da exploração intensiva de pastagens. In: SIMPÓSIO SOBRE MANEJO DE PASTAGENS. 13., 1996, Piracicaba. Anais... Piracicaba: Fundação de Estudos Agrários Luiz de Queiroz, 1996. p.15-97.

ONDEI, V. Reportagem de capa: abençoada água. Revista DBO Rural, n.220, p.44-52, 1999.

PARSONS, A.J.; PENNING, P.D. The effect of the duration of regrowth on photosynthesis, leaf death and the average rate of growth in a rotationally grazed sward. Grass and Forage Science, v.43, n.1, p.15-27, 1988.

REGO, F.C.A.; CECATO, U.; CANTO, M.W. et al. Qualidade do capim-tanzânia (Panicum maximum jacq. Cv. Tanzânia1) manejado em diferentes alturas, sob pastejo. In: REUNIÃO ANUAL DA SOCIEDADE BRASILEIRA DE ZOOTECNIA, 38., 2001, Piracicaba. Anais... Piracicaba: Sociedade Brasileira de Zootecnia, 2001. CD-ROM. Forragicultura.

SBRISSIA, A.F.; SILVA, S.C. O ecossistema de pastagens e a produção animal. In: REUNIÃO ANUAL DA SOCIEDADE BRASILEIRA DE ZOOTECNIA, 38., 2001, Piracicaba. Anais... Piracicaba: Sociedade Brasileira de Zootecnia, 2001. CD-ROM.

SILVA, S.C.; PASSANEZI, M.M.; CARNAVALLI, R.A. et al. Bases para o estabelecimento do manejo de Cynodon sp. para pastejo e conservação. In: SIMPÓSIO SOBRE MANEJO DE PASTAGENS, 15., 1998, Piracicaba. Anais... Piracicaba: Fundação de Estudos Agrários Luiz de Queiroz, 1998. p.129-150.

UNIVERSIDADE FEDERAL DE VIÇOSA - UFV. Central de processamento de dados UFV/CPD. Manual de utilização do programa SAEG (Sistema para análises estatísticas e genéticas). Viçosa, MG: UFV, 1993. 59p.

VEIGA, J.B.; MOTT, G.O.; RODRIGUES, L.R.A. Capimelefante anão sob pastejo. II - Valor nutritivo. Pesquisa Agropecuária Brasileira, v.20, n.8, p.937-944, 1985.

WHITHEMAN, P.C. Tropical pasture science. New York: Oxford University Press, 1980. 392p. 